\title{
Trophic Structure and Carbon Flow Dynamics in the Pelagic Community of a Large Lake
}

\author{
Ursula Gaedke, Dietmar Straile, and Claudia Pahl-Wostl
}

\section{Introduction}

Understanding the flow and cycling of matter within food webs is a major objective of contemporary ecosystem research (e.g., Wulff et al. (1989) and literature cited therein). A number of investigations on carbon $(C)$ cycling in pelagic ecosystems focused on the role of the microbial loop (e.g., Ducklow et al. (1986), Jackson and Eldridge (1992), and Stone et al. (1993)). The present case study from large and deep Lake Constance aims to contribute to this partially controversial issue by evaluating separately the contribution of the microbial community to the nutrition of large zooplankton (i.e., the link-sink issue), and to the overall $\mathrm{C}$ flow dynamics. This is done by aggregating all species from the entire food web into two separate chains, one based directly on phytoplankton (called grazing chain in the following), and one relying energetically on dead organic matter taken up by osmotrophic bacteria (detritus chain). The organismal composition and the relative quantitative significance of both chains will be compared. Perceiving the food web as being composed of these two chains approximates the concept of distinguishing between a classical pelagic food chain (going from phytoplankton via crustaceans to fish) and a microbial loop. However, in contrast to the latter concept, we account explicitly for flows into and from the pool of dead organic material. Second, we do not allocate each plankton group to one of the chains entirely but compute the fractional contribution of each group to both chains according to its diet composition. For example, ciliates belong mostly to the grazing chain as they are predominantly herbivorous. However, additional grazing on bacteria and flagellates results in the allocation of some ciliate fraction to the detritus chain.

We employ different methodologies that rely on ataxonomical aggregations of the component organisms. C flow diagrams are analyzed using network analysis techniques which offer a systematic way of keeping track of the numerous feeding pathways upon which any given population within the network depends (Wulff et al., 1989). The aggregation of complex food webs into a chain of successive trophic levels sensu Lindeman has frequently been criticized owing to serious operational problems associated with the assignment of individual populations to discrete trophic levels (Cousins, 1985, 1987; Burns, 1989). We account for this problem by distinguishing between trophic positions and trophic levels as suggested, e.g., by Ulanowicz (1986, in press). The trophic position of a population is in general a noninteger value which reflects the average number of trophic transfers its food items have passed before consumption by the given predator. It is calculated as the weighted average of the lengths of a populations's various feeding pathways. For example, a predator satisfying two-thirds of its energy demands by herbivory and one-third by grazing on herbivores is assigned to a trophic position of $2 / 3 \cdot 2+$ $1 / 3 \cdot 3=2 \frac{1}{3}$. In contrast, the biomass and throughflow of discrete trophic levels is established by distributing all omnivorous populations over the respective trophic levels according to their diet compositions. Given the 
above-mentioned example, two-thirds of the biomass and ingestion of the predator are assigned to the second, and one-third to the third trophic level. Such an analysis of discrete trophic levels reveals the underlying trophic structure and trophic transfer efficiencies.

Alternatively, biomass size distributions are constructed by first allocating all organisms into logarithmically spaced size classes, and by then computing the biomass per size class. The steepness of a size spectrum's slope reflects the efficiency to transfer biomass from small to larger organisms which, in turn, is related to trophic transfer efficiencies due to the fact that in pelagic food webs (excluding bacteria) energy is transferred predominantly along a gradient of increasing body size (Gaedke, 1993). This approach does not involve the ambiguities implicated in the definition of trophic levels. A comparison of these efficiencies with those derived from network analysis establishes a link between size-dependent and trophic level-based food web descriptions. Both approaches gave consistent results for absolute values and seasonal trends of the trophic transfer efficiencies from phytoplankton to herbivores (Gaedke and Straile, 1994b).

Finally, based again on the compartmental approach, short-term flow dynamics are illustrated by simulating the movement of imaginary tracers through the food web. The redistribution and residence times of biomass initially fixed in the algal and bacterial compartments within the food web and its loss from the system by respiration and sedimentation are calculated for different seasonal phases.

The following evaluations show on one hand that the throughput of the detritus chain is great $(61 \%)$ as compared to the grazing chain in Lake Constance. On the other hand, the simulated tracer experiments suggest that most carbon is quickly respired within the detritus chain and microbial production is of minor importance for the nutrition of larger plankton or seasonal average (cp. Gaedke and Straile (1994a)).

\section{Sampling Site, Materials and Methods}

Large $\left(476 \mathrm{~km}^{2}\right)$ and deep $\left(z_{\max }=252 \mathrm{~m}\right)$ Lake Constance (in German: Bodensee) is situated at the northern fringe of the Alps $\left(47^{\circ} 50^{\prime} \mathrm{N}\right)$. It changed gradually from mesoeutrophic to more oligotrophic conditions during the period of investigation (19871991) owing to improvements of sewage treatment. The sampling site is located in the northwestern fordlike arm which has no major in-or outflows. Pelagic species composition, productivity, and population dynamics, as well as ecosystem properties, have been studied in detail throughout the last decade (e.g., Tilzer and Beese (1988), Güde (1990), Weisse et al. (1990), Geller et al. (1991), Müller et al. (1991), and Gaedke (1992, 1993)). The C flow within and between the microbial and classical food webs was investigated using mass-balanced $\mathrm{C}$ flow diagrams and network theory (Gaedke and Straile, 1994a).

Within a special collaborative program a large team sampled all plankton groups ranging from bacteria $\left(10^{-14} \mathrm{~g} \mathrm{C}\right.$ cell $\left.^{-1}\right)$ to carnivorous cladocerans $\left(10^{-4} \mathrm{~g} \mathrm{C}\right.$ ind $\left.^{-1}\right)$ weekly throughout the season (approximately biweekly in winter) since 1987 . They were counted by microscopy using different techniques. Individual body sizes or size frequency distributions were measured regularly to obtain biomass estimates. Original measurements of body sizes were converted to units of $\mathrm{C}$ using measurements from Lake Constance or the literature. References and further information on sampling and counting techniques and the computations of biomass size distributions are given by Gaedke (1992).

To establish mass-balanced C flow diagrams, the pelagic community was subdivided into eight living compartments (freeliving and attached bacteria, phytoplankton including autotrophic picoplankton (APP), small heterotrophic flagellates (about 1-10 $\mu \mathrm{m})$, ciliates, rotifers, predominantly herbivorous crustaceans (daphnids, Bosmina, Eudiaptomous), predominantly zooplanktivorous crustaceans (all life stages of cyclopoid copepods and the predatory cladocerans Leptodora kindtii and Bythotrephes longimanus), and pelagic fish (mainly zooplanktivorous coregones and perch, abundances of piscivores are strongly reduced by man)) (Figure 5.1, for details see Gaedke and Straile (1994a)). Additionally, one nonliving compartment was considered comprising the fraction of dissolved and particulate 


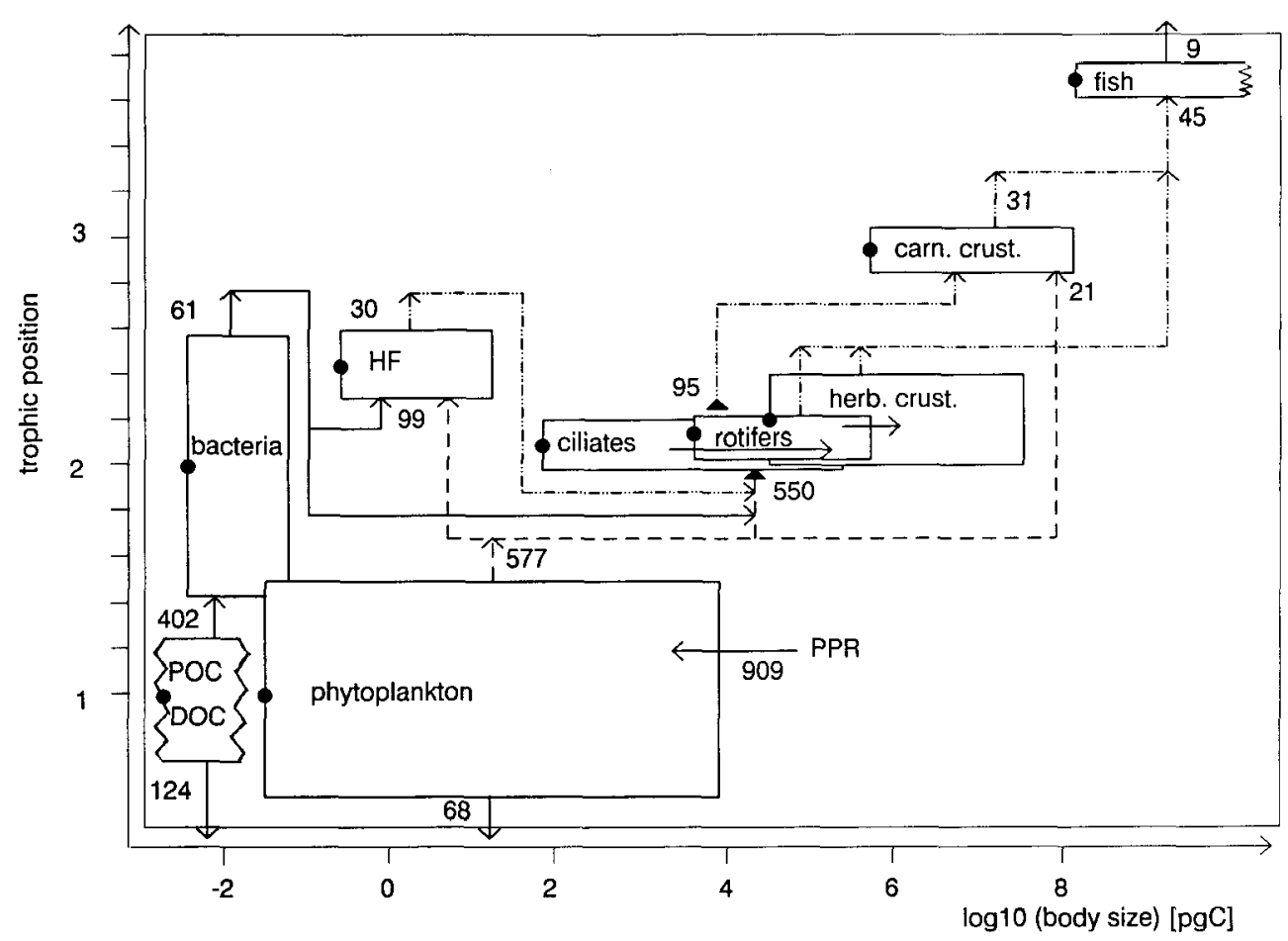

Figure 5.1. Carbon flow diagram of the pelagic food web of Lake Constance. The $x$-axis indicates the range of body weights and the $y$-axis the trophic position (see marker at the center of individual compartments) (annual average 1987). The size range covered by cyclopoid copepod nauplii $\left(2^{15}-2^{18}\right.$ $\mathrm{pg} \mathrm{C)}$ which were allocated to the carnivorous crustaceans, was neglected in the figure because they are predominantly herbivorous (adults are mostly zooplanktivorous). Fish reach body masses of more than $50 \mathrm{~g} \mathrm{C}$. The area of the compartments reflects relative production rates (the area of phytoplankton is reduced by $50 \%$ and the fish compartment is not on scale but considerably enlarged to improve the clarity of the figure). Respiration and fluxes into the POC/DOC pool were omitted. The numbers associated with fluxes provide ingestion and net production rates (i.e., the total amount of material ingested by the next trophic level) ( $\mathrm{mg} \mathrm{C} \mathrm{m}^{-2} \mathrm{~d}^{-1}$ ) for the uppermost $20 \mathrm{~m}$ of the water column.

detritus chain, - - - - grazing chain, _...... combination of both chains, HF stands for small heterotrophic flagellates. Fluxes crossing system boundaries represent exports by sedimentation and fish yield.

organic matter which participates in the biotic $\mathrm{C}$ cycle (called POC/DOC pool in the following). Production estimates were either derived from direct measurements (for autotrophs, bacteria, and heterotrophic flagellates) or calculated using weight-specific growth rates and abundance measurement. Allocation of prey production to omnivorous predators was based on the relative share of each predator to total predator production unless experimental evidence suggested different diet compositions. Except for all algae, the entire production of unicellulars was consumed by larger organisms on annual average. Further information and references on production measurements, diet compositions, growth efficiencies, and the mass-balancing procedure are provided by Gaedke and Straile (1994a). Composition of trophic levels were calculated separately for the grazing and detritus chain by modifying the software package NETWRK (Ulanowicz and Kay, 1991).

To trace the passage of algal and bacterial $\mathrm{C}$ through the food web and its elimination from the system by respiration and sedimentation, dynamic linear models were created for each seasonal period based on standing stocks and the $\mathrm{C}$ flow diagram as outlined above (Anderson, 1983). Residence times within individual compartments are calculated as the ratio of biomass, $B$, to compart- 
mental input, $I$ (which equals the total output including respiration, production, $P$, release of organic material, and changes of standing stocks). Thus, they differ from common biomass turnover times (i.e., $B / P$ ratios) by the gross growth efficiency, $K_{1}=P / I$, accounting for the considerable fraction of the input which is not converted into biomass but respired or released as dead organic matter (i.e., $B / I=K_{1} \cdot B / P$ ). We assumed that twothirds of the released organic matter is refractory over the short time periods under consideration. Changing this fraction to one-third hardly affects the results.

The annual cycles were subdivided into seven to ten time intervals of unequal length which reflect different stages in plankton succession $(1=$ late winter; 2 and $3=$ early and late spring; $4=$ clear-water phase; $5=$ early summer with daphnid maximum; $6=$ heavy flooding (in 1987 only); 7 and $8=$ mid and late summer; 9 and $10=$ early and late autumn; the last two stages are partially omitted from the present analysis; for details see Geller et al. (1991)). For each time interval, separate biomass size distributions and flowcharts were obtained by averaging the measurements over the three to six respective sampling dates. Steady-state conditions were assumed within each time interval. Observed changes of standing stocks between successive time intervals were accommodated in the compartmental approaches by adding respective flows representing population growth or decline.

\section{Results}

Diagrams displaying quantitative $\mathrm{C}$ flows along the gradients of body size and trophic positions provide a condensed description of the trophic structure and function of pelagic ecosystems (Figure 5.1). As postulated by Pahl-Wostl (1993), a correlation between body size and trophic position exists within the grazing chain going from phytoplankton via algivorous zooplankton to fish which dominates the C-flow. Ciliates, rotifers, and herbivorous crustaceans which are mostly consumed by crustaceans, represent the major herbivores. They form a continuum with respect to body size and related parameters and have similar trophic positions in the food web model of Lake Constance suggesting that they may be regarded on annual average as a single functional unit. Predation by herbivorous crustaceans on ciliates and rotifers as well as the intracompartmental predation of ciliates and rotifers is of minor importance as judged by the contribution to the predators' diet. Large carnivorous crustaceans (cladocerans) repackage the smaller herbivores especially in summer, and provide a suitable food source for planktivorous fish. If following International Biological Program (IBP) standards the autochthonous organic material is irrespective of its origin appointed to the first trophic level, bacteria belong to the second trophic level, and heterotrophic flagellates are approximately on position 2.5. The latter are grazed by predominantly herbivorous organisms which are larger than the flagellates but on a lower trophic position since heterotrophic flagellates contribute only marginally to their diet. Size and trophic position are also correlated within the detritus chain. However, under these assumptions organisms of the detritus chain are much smaller than members of the grazing chain at a similar trophic position (Figure 5.1). The plankton organisms form a continuum in size, but different functional groups overlap little in size.

An analysis of the organismal composition of discrete trophic levels reveals that consumer groups (besides bacteria) are scattered over three or more levels (Figure 5.2a). Organisms on the third trophic level range from small bacterivorous flagellates to fish relying on algivorous crustaceans. Fish constitutes approximately half of the fourth and fifth trophic levels and strongly dominates the higher ones. Otherwise, the correspondence between trophic levels and distinct plankton groups is weak. The number of potential feeding pathways increases with the trophic position and the energetic basis of individual population on the third or a higher trophic level cannot be evaluated any more from the organismal composition of discrete trophic levels.

Considering the grazing and the detritus chain separately improves the clarity of the trophic analysis as it yields more homogenous compositions of individual trophic levels with respect to, e.g., body size, trophic interactions, and taxonomy. It allows an approximate identification of most trophic lev- 

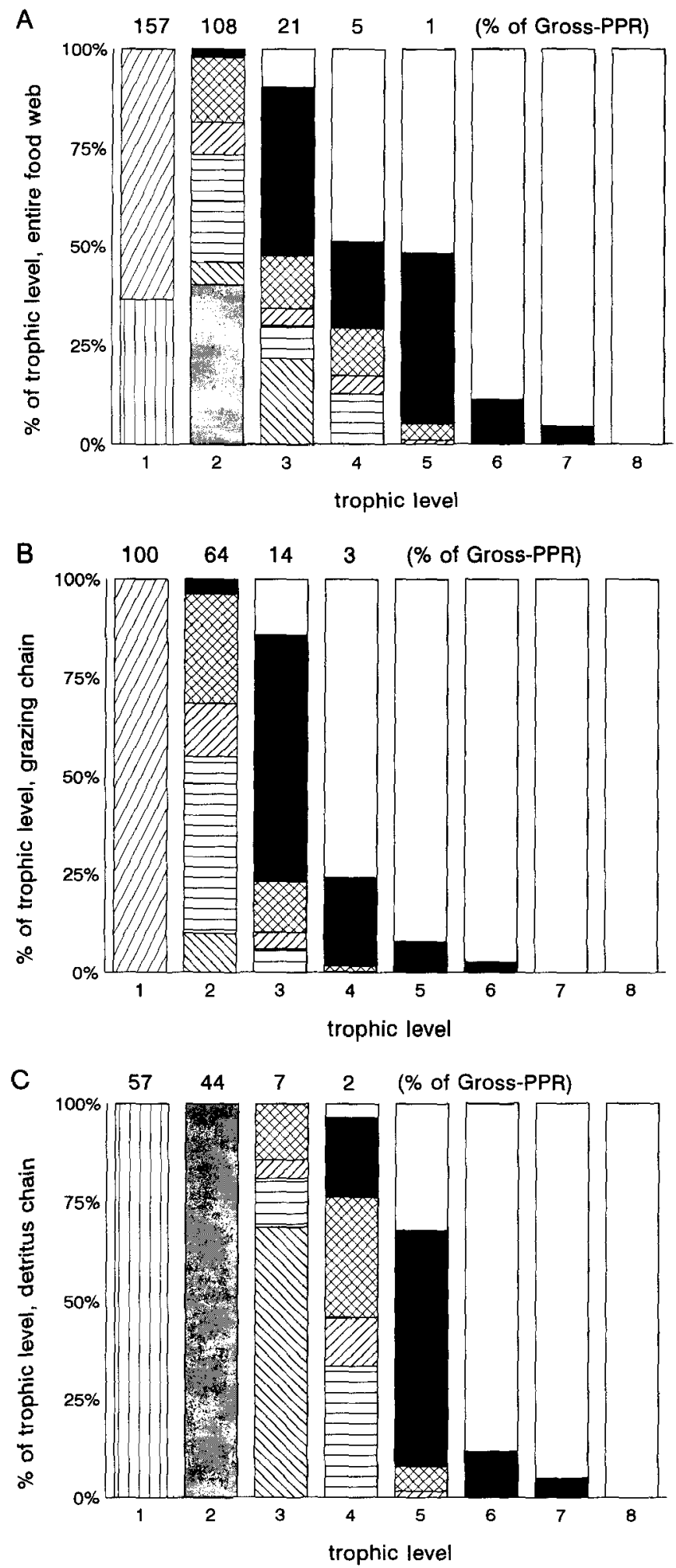
els with real counterparts (e.g., major taxonomical groups) when ciliates, rotifers, and herbivorous crustaceans are regarded as one functional unit. Primary production and DOC are exploited by different sized organisms. Herbivores are orders of magnitude larger than bacteria. Consequently, the aggregation of biomass into similar sized food items along the detritus chain demands approximately two additional trophic transfers (Figures $5.2 \mathrm{~b}$ and 5.2c). Consequently, carnivorous crustaceans and fish are approximately two trophic levels higher in the detritus chain, and rely energetically almost entirely on the grazing chain. Losses associated with energy transfer reduce the fraction of total fish consumption which passes through the bacterial compartment (i.e., the total dependency coefficient) to $2-8 \%$ (annual average $5.5 \%$ ).

The quantitative importance of both chains can be evaluated by comparing the throughput of corresponding trophic levels and the entire chains. In our food web model, the detritus chain is driven exclusively by autochthonous organic substances which are either released directly by autotrophs (5-15\% of gross primary production), or by organisms at higher trophic levels. Remarkably, these losses amount to $57 \%$ of gross primary production (Figure 5.2c) and enable a second chain with $61 \%$ of the throughput (defined as the sum of fluxes between trophic levels) of the original one. The large throughput of the detritus chain derives from the large fluxes into and from the POC/DOC pool (Figure $5.2 \mathrm{c}$ ). Ingestion rates of bacteria, which correspond to herbivores in the grazing chain, amount to nearly $70 \%$ of the algivores. The third trophic level of the detritus chain, which is dominated by small heterotrophic flagel- lates, reaches half of the ingestion rates of the third level of the grazing chain which consists mainly of carnivorous crustaceans (Figures 5.2b and 5.2c). Apparent reductions of trophic transfer efficiencies at higher trophic levels of the grazing chain are caused by the export of fish production from the system by fishery which thus prevents a consumption by higher trophic levels within the lake.

The efficiency of biomass transfer from the first to the third trophic level along the grazing chain varies seasonally between $1 \%$ and almost 10\% (Figure 5.3). This biomass transfer reflects the major flow of energy within the plankton food web (Figure 5.2b) and may be related to the slope of corresponding plankton biomass size spectra (excluding bacteria). The latter are influenced by the predator-prey weight ratios and the efficiency to transfer biomass from one trophic level to the next. The slopes exhibit a similar seasonal trend.

The velocity by which organic matter is channeled through, and lost from, the food web (including the POC/DOC pool) is illustrated in a model simulation by tracing the passage of one arbitrary unit of primary production (as measured by the ${ }^{14} \mathrm{C}$ technique), and of organic matter taken up by bacteria through the $\mathrm{C}$ flow diagram. These substances will be called tracers because of the resemblance with a tracer experiment where a pool is labeled at time zero. Residence times of organic matter within the entire food web are mainly influenced by respiration rates since export rates by sedimentation and fish yield are considerably smaller (Figure 5.1).

Residence times of primary production within the entire food web vary seasonally.

Figure 5.2. Composition of trophic levels regarding (a) the entire food web (feeding cycles excluded); (b) the part of the food web ascending directly from primary producers ("grazing chain"); and (c) the part of the food web based on organic matter recycled via the POC/DOC pool ("detritus chain"). The contribution of individual compartments is inferred from their relative ingestion rates. The numbers on top of the bars in Figures 5.2b and 5.2c represent the relative input into the respective trophic level as compared to gross primary production (in \%) (values below $0.5 \%$ are not given). Export of fish production by man reduces the apparent efficiency of the trophic levels dominated by fish.

Symbols:

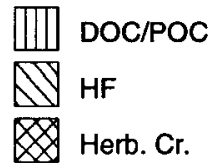

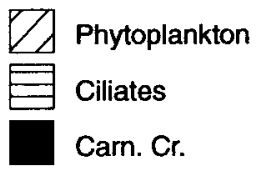

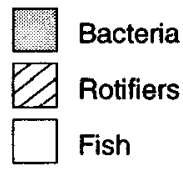




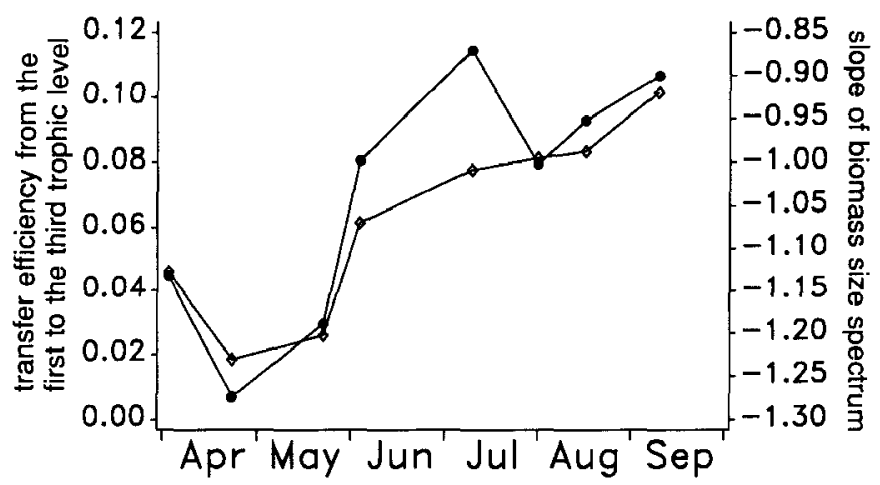

Figure 5.3. Comparison of transfer efficiencies and their seasonal changes for the uppermost $20 \mathrm{~m}$ of the water column in 1987. Open rectangles: Trophic transfer efficiency from the first (algae) to the third (mostly crustaceans) trophic level of the grazing chain. Dots: Slopes of normalized biomass size distributions indicating the efficiency to transfer from small (e.g., algae) to large organisms (e.g., crustaceans) within the plankton community).

They are low in spring when $50 \%$ of the algal standing stock is lost from the system after two days (Figure 5.4a). Losses are strongly dominated by bacterial respiration followed by algal dark respiration, ciliate respiration, and sedimentation. In early and midsummer, system residence times are two to three times as long although algal standing stocks and primary production are lower in absolute values and in relation to the biomass and production of bacteria and other heterotrophs. Dissipation is slower during these periods since larger consumers with slower process rates dominate, i.e., the weight-specific respiration rate is lower.

The redistribution of the tracer within the food web exhibits pronounced seasonal changes as well. In early spring, half of the tracer which still resides in the food web has left the algal compartment after two days (Figure 5.5a). Primary production is passed quickly to the ciliate compartment and then to the POC/DOC pool. Thus, cycling of considerable amounts of $\mathrm{C}$ is performed within a few days. Tracer accumulation in crustaceans which have somewhat lower $I / B$ ratios, follows with a time lag of a few days. The relative amount of recycled tracer residing in the POC/DOC pool and the bacteria gains some importance after about three days. The fish compartment representing the top predators with lowest $I / B$ ratios receives only a small fraction of the tracer entering the system (Figure 5.2). Its relative importance, however, increases steadily as time proceeds. In early summer, primary produced $C$ not yet respired leaves the algal compartment faster than in early spring, and daphnids strongly dominate the passage of the tracer until it accumulates in fish (Figure 5.5b). The plankton community is more diverse in midsummer which is reflected by a more uniform distribution of primary production over the different compartments (Figure 5.5c). The fraction of primary production residing in the algal compartment resembles that in early spring. However, herbivores and their predators have longer residence times, which results in a slower flow to bacteria and fish than in early spring.

System residence times of organic material taken up by bacteria are shorter than those of primary produced carbon (Figure 5.4) because a large fraction of the bacterial consumption is directly respired (Figures 5.1 and 5.2) especially in spring, causing high $I / B$ values. Additionally, bacterial production is mainly consumed by small heterotrophic flagellates with high process rates. The redistribution of the material taken up by bacteria within the food web compared to that of primary production reflects first differences caused by the food web structure. For example, heterotrophic flagellates contain relatively more of the tracer during the first days. Second, a larger fraction of the bacterial consumption which has not yet been respired resides in the bacterial compartment than primary production does in the algal compartment since bacterial $P /$ $B$ ratios are considerably lower than those of autotrophs. 

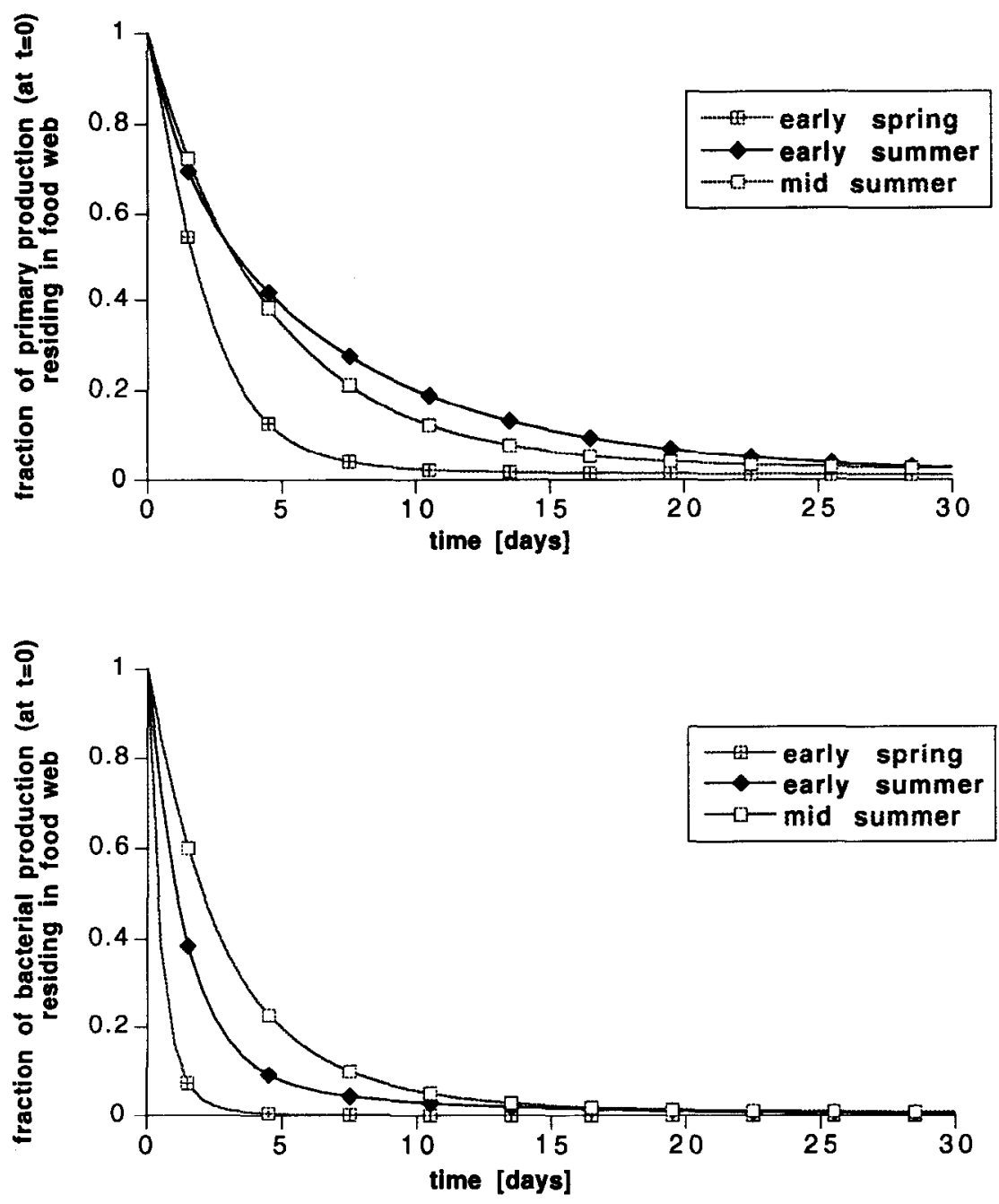

Figure 5.4 (a) System residence times of primary production during different stages of the seasonal succession in 1987. The functions illustrate the fraction of primarily produced carbon at $t=0$ which still resides in the food web.

(b) as (a) but for organic material taken up by osmotrophic bacteria.

\section{Discussion}

\section{Critical Appraisal of Results}

A comparison of the quantitative importance of individual trophic levels of the grazing and the detritus chain and their organismal composition reveals that the recycled organic matter which is metabolized by bacteria contributes considerably to the overall $\mathrm{C}$ cycle in Lake Constance (but see below) (Figure 5.2). It explains equally well, however, why this material is only of limited value to the nutrition of large organisms. Primary produc- tion and DOC form very different starting points of the two food chains. They differ with respect to, e.g., their biochemical composition, nutrient and caloric content, and their system residence times. However, differences in their potential for exploitation appear to be of even greater importance for the organization of the pelagic food web. In pelagic ecosystems the suitability of an organism as a potential food item for a predator of a given size depends to a large extent on its size because predators tend to swallow their prey whole. About half of the feeding interactions occur between organisms dif- 


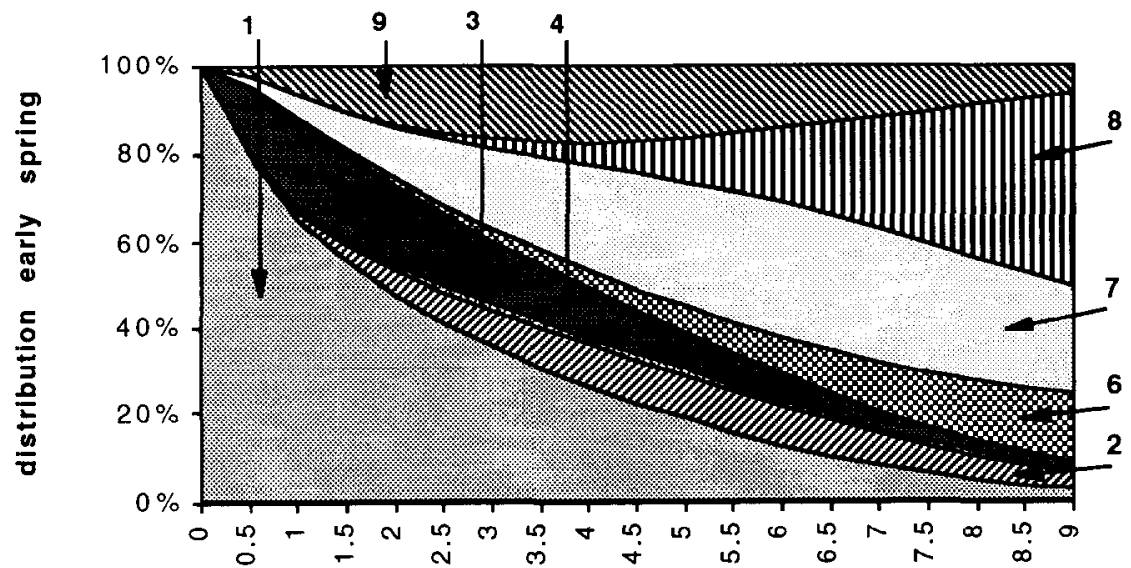

(a)
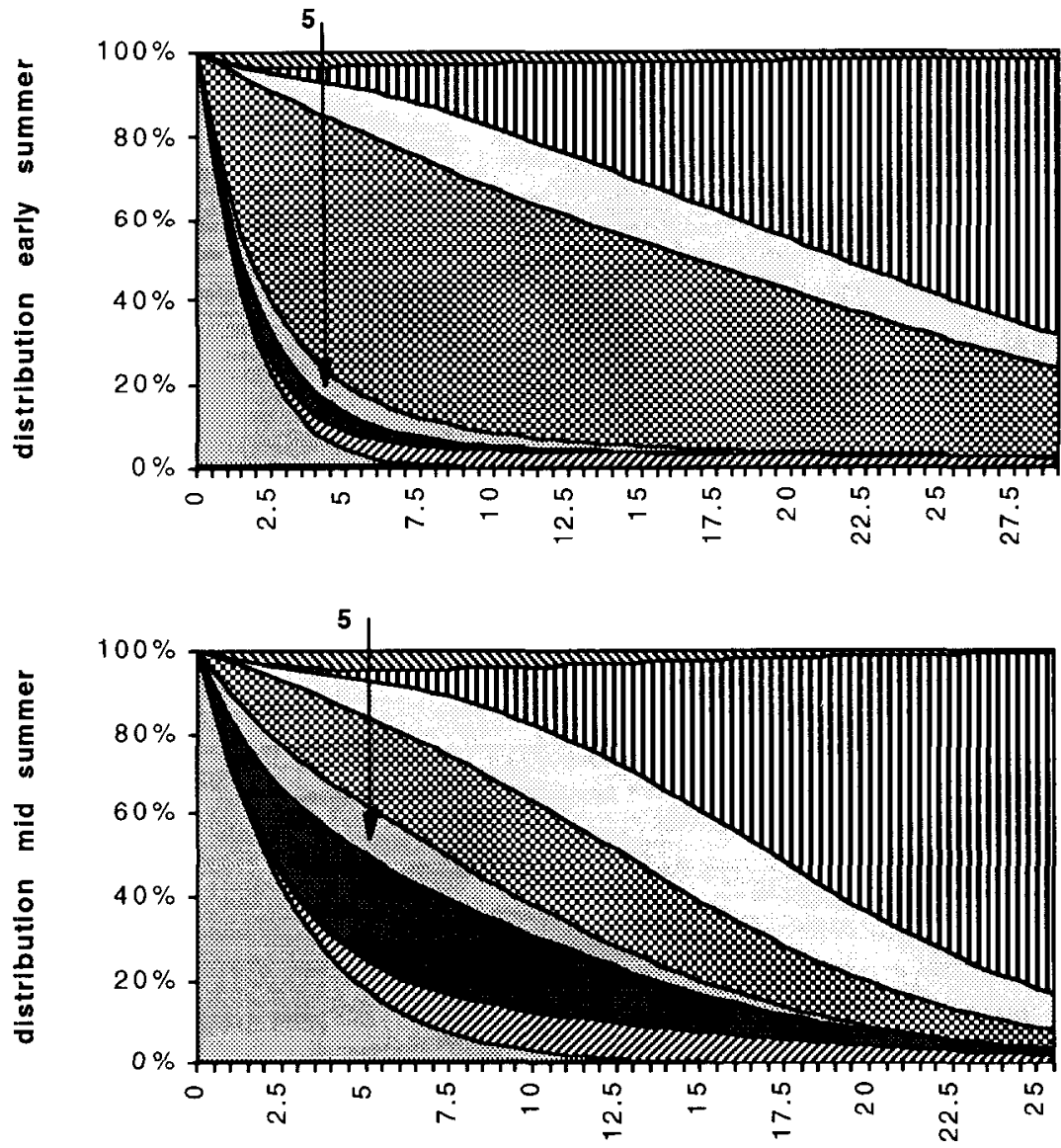

(c)

\section{time [days]}

Figure 5.5. Results from model simulations following the distribution of carbon that is fixed by primary production. The figures display the respective time intervals until $97 \%$ of the tracer is lost from the system (a) Early spring; (b) early summer; (c) high summer 1987. 1=phytoplankton; 2=bacteria; $3=$ heterotrophic flagellates; $4=$ ciliates; 5 =rotifers; 6 =herbivorous crustaceans; $7=$ carnivorous crustaceans; $8=$ fish; $9=$ POC $/$ DOC pool. 
fering in weight by a factor of $100-10,000$ in the plankton food web of Lake Constance (Gaedke, unpublished).

Autotrophs range in size from about 0.05 to $10^{4} \mathrm{pg} \mathrm{Ce} \mathrm{Cell}^{-1}$ and gross primary production is transferred to algal biomass with an efficiency of $64 \%$ in our food web model (Figure 5.2b). Body mass of herbivores varies between 100 and $3 \cdot 10^{7} \mathrm{pg} \mathrm{C}$. In contrast, dead organic material is almost exclusively utilized by osmotrophic bacteria (typical size range: $0.005-0.03 \mathrm{pg} \mathrm{Cell}^{-1}$ ) in our ecosystem and bacterial growth efficiencies may range from 10 to $30 \%$. Aggregation of bacterial biomass into the size of small autotrophs (e.g., heterotrophic flagellates with approximately $0.1-16 \mathrm{pg} \mathrm{C}^{-1}{ }^{-1}$ ) requires yet another trophic transfer. This repackaging of biomass into larger food items expends a considerable amount of energy, which results in a low contribution of the detritus chain to the nutrition of larger zooplankton in Lake Constance (Gaedke and Straile, 1994a) and comparable ecosystems (e.g., Hagström et al. (1988)).

Simulation of an imaginary tracer experiment summarizes the effects of structural changes like the seasonal shift towards larger organisms and increasing transfer efficiencies on the dynamics of $\mathrm{C}$ traveling through the food web. It emphasized that bacterial respiration, which is high as compared to algal dark respiration, represents a major loss of $\mathrm{C}$ from the system which is then not available for higher trophic levels. These findings are roughly in accordance with other studies (e.g., Baird and Ulanowicz (1989) and Jackson and Eldridge (1992)). In an experiment only $2 \%$ of the label initially fixed from ${ }^{14} \mathrm{C}$ glucose was transferred to larger organisms and a large fraction was directly respired (Ducklow et al., 1986). Except in winter, system residence times of carbon in Lake Constance were shorter than those calculated for the uppermost layer of a planktonic system off Southern California (Jackson and Eldridge, 1992). Low system residence times and rapid cycling of $C$ within the food web emphasizes the highly dynamic behavior of the system which has little storage capacity during the growing season at this level of organization. This implies for example that an interruption of primary production for just a few days causes starvation of herbivores since the internal energy storage of individual organisms tends to be low as well. Residence times and redistribution patterns of carbon and nutrients differ in general (Jackson and Eldridge, 1992).

\section{Definition of the Trophic Position of Nonliving Organic Material}

Dead allochthonous material is commonly treated as second external energy input like light energy which implies that its consumers (bacteria, detrivores) are assigned to the first trophic level like autotrophs. In contrast, the treatment of recycled autochthonous material differs between studies. Burns et al. (1991) allocated the dead organic matter to the trophic position of its sources, i.e., bacteria and detrivores are one level higher than the organisms which released the material. This technique results in a theoretically unlimited number of trophic levels, and an extremely heterogeneous composition of the higher trophic levels (e.g., bacteria and bacterivores are combined with top predators of the grazing chain).

In the present and numerous other (IBP) studies autochthonous organic matter was assigned to the first trophic level like autotrophs (e.g., Wulff et al. (1989)). This equating of herbivory and detrivory in the trophic sense was motivated by ecosystem studies where a large fraction of primary production is consumed indiscriminately before or after death (Ulanowicz, in press). It reflects the perception of bacteria as secondary producers in autochthonous systems. When changing from units of carbon to nutrients primary producers are allocated to the same level as bacteria indicating that they are now competitors for the same resource. Drawbacks of this definition include that, depending on their classification of being allochthonous or autochthonous, substances of equal exploitability may be assigned to different trophic levels. The combination of living and nonliving material in the first trophic level complicates the ecological interpretation of the trophic analysis and the transfer efficiencies according to our opinion. Again, the compartmental composition of individual trophic levels may be very heterogeneous (Figure 5a).

We suggest that regarding in contrast all dead organic material as external energy in- 
put into the living system circumvents these problems and avoids the necessity of a distinction between allochthonous and autochthonous material which depends critically on the definition of the system boundaries. The allochthonous mass balance and its contribution to the entire energy input may be acknowledged separately. This definition relates the nonliving inputs into the first living compartment to each other, i.e., the energy embodied in dead organic material is treated like light energy used for autochthonous gross primary production. It yields a clear and consistent interpretation of the various measures, at least if the grazing and detritus chain are considered separately. The trophic level now reflects for all organisms the number of assimilation (not transfer) events the material has passed since it entered the living system. The transfer efficiencies between trophic levels become comparable as they all include metabolic losses. The tendency towards a more homogenous composition of individual trophic levels facilitates food web analyses and comparisons with growth efficiencies and life history features of dominating groups.

Independent of its trophic level, the POC/ DOC pool should not be treated like a living compartment in trophic analyses because otherwise one step of the trophic ladder is performed without dissipation of energy, which is otherwise characteristic for all trophic transfers (cp. Burns et al. (1991)). Besides sedimentation, the input into the POC/DOC pool equals the output since losses, e.g., by respiration, are lacking, and counting both fluxes as partially done by the program NETWRK should be avoided. It provokes an overestimation of the quantitative importance of the detritus chain when compared to the grazing chain, and rather odd results are obtained when calculating, e.g., average path lengths, for our ecosystem. A comprehensive discussion of this issue will be given elsewhere.

Conceptualizing the Food Web as a Trophic Continuum or by a Modified Concept of Trophic Levels

The similar seasonal trends of the transfer efficiencies evaluated by compartmental trophic analysis and from slopes of biomass size spectra indicate that the trophic level and the trophic continuum concept may both be suitable conceptualizations of pelagic food webs. Similarities may originate to a large degree from the relationship between body size and trophic position (Figure 5.1). Deviations in seasonal trends partially arise from temporal changes in standing stock which were only accounted for in the trophic analysis.

To conclude, diagrams displaying trophic interactions and trophic positions of component organisms versus body size appear as a suitable tool to summarize the trophic structure and function of pelagic communities. A simple aggregation of a pelagic food web into trophic levels and one feeding chain does not provide much insight into its functioning owing to the different exploitation of primary producers and dead organic material in pelagic systems. The flow into the POC/DOC pool represents a major $C$ flux within the ecosystem and enables a second food chain with a throughput of considerable quantitative importance. From the viewpoint of large zooplankton and fish, however, it is of low quality and minor importance owing to the small cell sizes of the first trophic levels of the detritus chain. Transfer efficiencies derived from trophic analysis and size-based food web descriptions exhibit similar seasonal trends.

\section{Acknowledgments}

Data acquisition and the present study were performed within the Special Collaborative Program (SFB) 248 "Cycling of Matter in Lake Constance," supported by Deutsche Forschungsgemeinschaft. We thank all scientists who developed the biological database. Martin Lang provided information on the food web structure and Hans Güde contributed valuable discussions on underlying assumptions. R. Ulanowicz, P. De Ruiter, M. $V$ anni, and an anonymous reviewer improved the content and style of the manuscript.

\section{References}

Anderson, D. H. 1983. Compartmental Modeling and Tracer Kinetics. Springer Verlag, Berlin.

Baird, D. and R. E. Ulanowicz. 1989. The seasonal dynamics of the Chesapeake bay ecosystem. Ecological Monographs 59:329-364. 
Burns, T. 1989. Lindeman's contradiction and the trophic structure of ecosystems. Ecology 70:1355-1362.

Burns, T. P., Higashi, M., Wainwright, S. C., and B. C. Patten 1991. Trophic unfolding of a continental shelf energy-flow network. Ecological Modelling 55:1-26.

Cousins, S. 1985. The trophic continuum in marine ecosystems: Structure and equations for a predictive model. In Ecosystem Theory for Biological Oceanography, ed. R. E. Ulanowicz and T. Platt. Canadian Bulletin of Fisheries and Aquatic Sciences 213:76-93.

Cousins, S. 1987. The decline of the trophic level concept. Trends in Ecology and Evolution 2:312-316.

Ducklow, H. W., D. A. Purdie, P. J. LeB. Williams, and J. M. Davies. 1986. Bacterioplankton: A sink for carbon in a coastal marine plankton community. Science 232:865-867.

Gaedke, U. 1992. The size distribution of plankton biomass in a large lake and its seasonal variability. Limnology and Oceanography 37:12021220.

Gaedke, U. 1993. Ecosystem analysis based on biomass size distributions: A case study of a plankton community in a large lake. Limnology and Oceanograpyhy 38:112-127.

Gaedke, U. and D. Straile. 1994a. Seasonal changes of the quantitative importance of protozoans in a large lake-An ecosystem approach using mass-balanced carbon flow diagrams. Marine Microbial Food Webs 8:163-188.

Gaedke, U. and D. Straile. 1994b. Seasonal changes of trophic transfer efficiences in a plankton food web derived from biomass size distributions and network analysis. Ecological Modelling 75/76:435-445.

Geller, W., R. Berberovic, U. Gaedke, H. Müller, H.-R. Pauli, M. Tilzer, and T. Weisse. 1991. Relations among the components of autotrophic and heterotrophic plankton during the seasonal cycle 1987 in Lake Constance. Verh. Int. Verein. Limnol. 24:831-836.

Güde, H. 1990. Bacterial production and the flow of organic matter in Lake Constance. In Large Lakes-Ecological Structure and Function, eds. M. M. Tilzer, and C. Serruya, pp. 489 502. Brock/Springer, Berlin.

Hagström, A., F. Azam, A. Andersson, J. Wikner, and F. Rassoulzadegan. 1988. Microbial loop in an oligotrophic pelagic marine ecosystem: Possible roles of cyanobacteria and nanoflagellates in the organic fluxes. Mar. Ecol. Prog. Ser. 49:171-178.

Jackson, G. A., and P. M. Eldridge. 1992. Food web analysis of a planktonic system off Southern California. Prog. Oceanog. 30:223-251.

Müller H., A. Schöne, R. M. Pinto-Coelho, A. Schweizer, and T. Weisse. 1991. Seasonal succession of ciliates in Lake Constance. Microbial Ecology 21:119-138.

Pahl-Wostl, C. 1993. Food webs and ecological networks across temporal and spatial scales. Oikos 66:415-432.

Stone, L., T. Berman, R. Bonner, S. Barry, and S.W. Weeks 1993. Lake Kinneret: A seasonal model for carbon flux through the planktonic biota. Limnology and Oceanography 38:1680 1695.

Tilzer, M. M. and B. Beese. 1988. The seasonal productivity cycle of phytoplankton and controlling factors in Lake Constance. Schweiz. Z. Hydrol. 50:1-39.

Ulanowicz, R. 1986. Growth and development. Ecosystems Phenomenology. Springer-Verlag, Berlin.

Ulanowicz, R. E. Ecosystems and trophic foundations: Lindeman exonerata. In Complex Ecology: The Part-Whole Relationship in Ecosystems, eds. B. Patten and S. Jörgensen. PrenticeHall, NJ.

Ulanowicz, R. E. and J. Kay. 1991. A package for the analysis of ecosystem flow networks. Environmental Software 6:131-142.

Weisse, T., H. Müller, R. M. Pinto-Coelho, A. Schweizer, D. Springmann, and G. Baldringer. 1990. Response of the microbial loop to the phytoplankton spring bloom in a large prealpine lake. Limnology and Oceanography 35:781794.

Wulff, F., F. G. Field, and K. H. Mann, eds. 1989. Network Analysis in Marine Ecology. Methods and Applications. Coastal and Estuarine Studies, Volume 32, Springer-Verlag, Berlin. 